\title{
Разнообразие почвенной фауны Хибин (итоги 10-летних исследований)
}

\author{
Зенкова И.В.
}

Институт проблем промышленной экологии Севера ФИЦ КНЦ РАН, Anamumbl, i.zenkova@ksc.ru

Аннотация. Обобщены результаты 10-летних (2008-2018 гг.) почвенно-зоологических исследований автора в Хибинах. В межгорных долинах и на склонах 10 гор в пределах основных растительных поясов (горно-таежного, горно-тундрового, пояса березовых криволесий и гольцовых пустынь) в градиенте высот от 220 до 1100 м над ур. м. обследовано 45 биоценозов. Методами отбора образцов подстилки и установки почвенных ловушек с формалином выявлено более 450 видов беспозвоночных при наибольшем разнообразии паукообразных и насекомых и преобладании обитателей яруса напочвенной растительности (герпетобионтов) над представителями почвенной фауны. Более 40 видов являются новыми для Мурманской области. В целом почвенная фауна Хибин имеет бореальный облик; присутствие видов с разными преференциями (кальцефильных, свето- и тенелюбивых, мезо- и гигрофильных, холодолюбивых и термофильных) свидетельствует о гетерогенности условий обитания в пределах заполярного горного массива.

Ключевые слова: Хибины, горные почвы, почвенные и герпетобионтные беспозвоночные, разнообразие.

\section{The diversity of soil fauna of the Khibiny Mountains (the results of ten-year researches)}

\author{
Zenkova I.V. \\ Institute of North Industrial Ecology Problems Kola SC RAS, Apatity, i.zenkova@ksc.ru
}

\begin{abstract}
The results of ten-year soil-zoological researches in the Khibiny Mountains are summarized. In total, 45 biocenoses were investigated in 2008-2018 in the intermountain valley and on slopes of 10 mountains within the belts of mountain taiga, birch crooked forests, mountain tundra, and a high-altitude desert in the gradient from 250 to $1100 \mathrm{~m}$ above sea level. More than 450 species of invertebrates were identified using methods of litter sampling and pitfall traps with formalin. The greatest diversity of arachnids and insects, and the predominance of herpetobiont invertebrates over the soil fauna were found. More than 40 invertebrate species appear new to the Murmansk region. In general, the mountain fauna is characterized as boreal. The presence of stenotopic species with different preferences reflects the heterogeneity of habitat conditions within the polar mountain range.
\end{abstract}

Key words: Khibiny, mountain soils, soil and herpetobiont invertebrates, diversity.

\section{Краткая история фаунистических исследований}

Первые научные сведения по фауне Хибин были получены в ходе финских и шведских экспедиций 1861-1913 гг. по «Кольской Лапландии»; материалы по выявленным видам жесткокрылых обобщены в работе Б. Поппиуса (Рoppius, 1905).

Целенаправленные исследования с 1930 г. проводили сотрудники зоогеографического отдела горной станции «Тиетта» Кольской базы АН СССР под руководством с.н.с. В.Ю. Фридолина. За первое десятилетие они выявили около 1000 видов насекомых и 90 в. позвоночных животных, в том числе тех, существование которых за Полярным кругом и не предполагалось. По заключению Фридолина (1931, 1932, 1934, 1936), фауна «Хибинской горной страны» характеризуется богатым разнообразием видов и разнородностью их зоогеографического происхождения. Открытые ландшафты горной тундры населяет древняя арктоальпийская биота, экосистемы горно-лесного пояса - эволюционно молодой комплекс бореальных и монтанных видов. В обоих поясах обитают виды и европейского, и сибирского происхождения, а также виды «...немногочисленные, очень древние, часть из которых реликтового характера». В те же годы были выполнены специальные исследования по насекомым-вредителям хвойных древостоев (жукам-короедам) и кровососущим комарам (Старк, 1931; Гуцевич, 1934). 
В последующие десятилетия в Хибинах проводили эпизодические исследования дождевых червей (Перель, 1979; Рыбалов, 2006), жуков - жужелиц и стафилинид (Россолимо, 1989; 1994), цикадовых (Ануфриев, 2000), чешуекрылых (Татаринов, Кулакова, 2009), шмелей (Потапов, Колосова, 2011), панцирных клещей (Karppinen, Krivolutsky, 1982; Леонов, Рахлеева, 2011, 2015), пауков (Камаев, 2010; Танасевич, Камаев, 2011). Было выявлено 4 в. дождевых червей при доминировании Lumbricus rubellus, численность которого в горах достигала нетипично высоких показателей $\left(130\right.$ экз./ $\left.\mathrm{M}^{2}\right)$ в сравнении с зональными подзолами. Среди жесткокрылых отловлено 17 в. жужелиц (Carabidae), 15 в. стафилинид (Staphylinidae), по 2 в. щелкунов (Elateridae) и долгоносиков (Curculionidae), 1 в. мягкотелок (Cantharidae). Из 50 в. дневных бабочек 40 в. признаны постоянными обитателями Хибин, а фауна булавоусых в целом - ярко выраженной борео-монтанной. Фауна шмелей при небогатом числе видов (11) оказалась разнородной по ареалогии из-за видов с арктическим (Bombus polaris), аркто-бореальным (B. balteatus, B. lapponicus), аркто-умеренным, бореальным, горно-бореальным и умеренным распространением. В тундровом поясе горы Вудъяврчорр обнаружено 50 в. панцирных клещей, в т.ч. новый для науки вид рода Parabelbella, в тундрах Ловозерского массива - 71 в. Как правило, в разных местообитаниях число видов клещей не превышало 15-30, число семейств - 10-15.

В июле 1998 г. в рамках организации национального парка «Хибины» было проведено энтомологическое обследование Хибинского и Ловозерского массивов. Собраны насекомые 200 видов из 8 отрядов (Эколого-экономическое ..., 1999).

\section{Итоги 10-летних исследований почвенной фауны Хибин сотрудниками ИППЭС}

Комплексные почвенно-зоологические исследования Хибин проводятся сотрудниками Института проблем промышленной экологии Севера, совместно со специалистами из других НИИ, с 2008 года (Зенкова и др., 2009, 2011а-в; Пожарская, 2012; Зенкова, Таскаева, 2012, 2013; Таскаева,

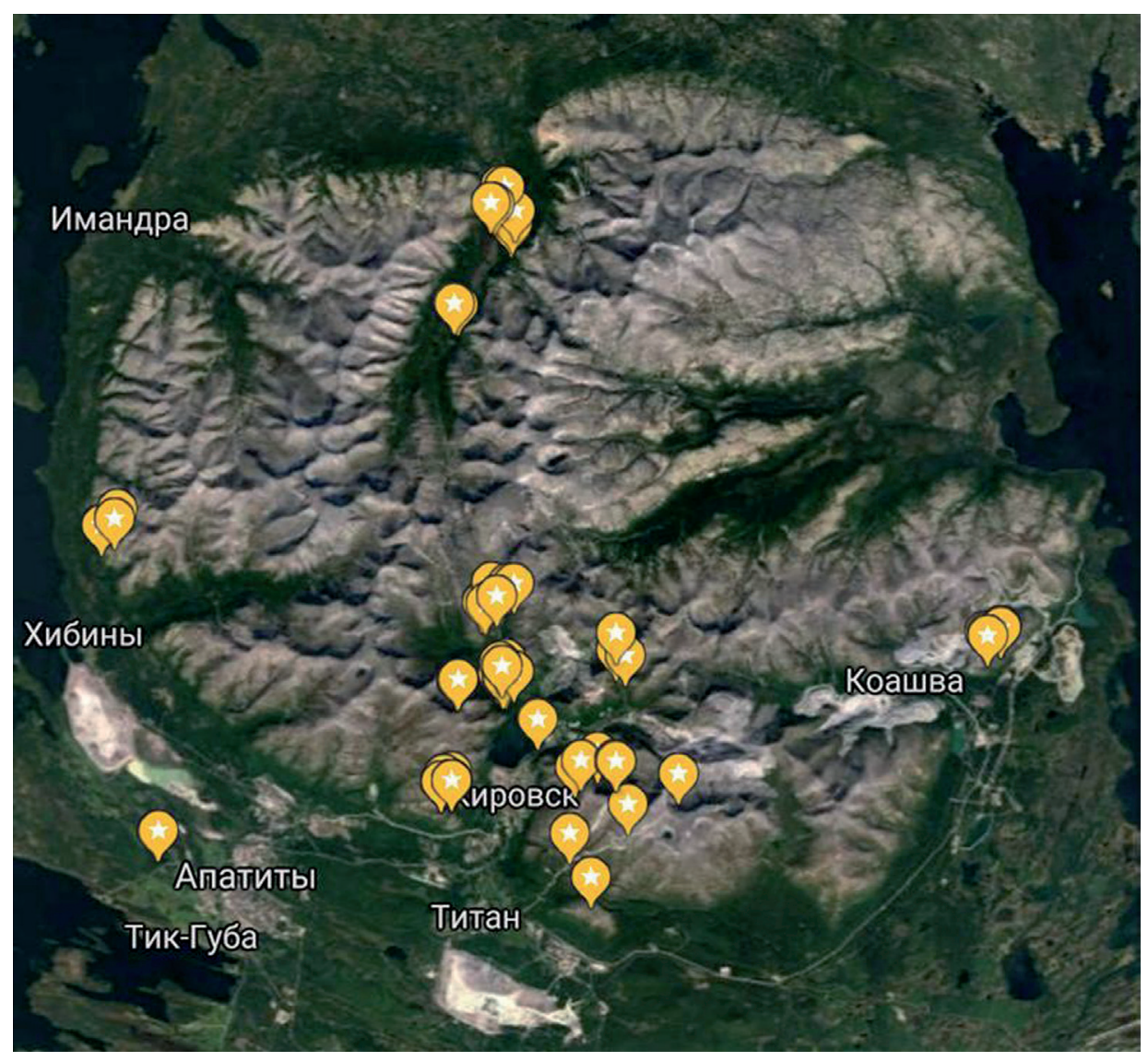

Рис. 1. Экосистемы, исследованные в Хибинах, в 2008-2018 гг.

Fig. 1. Ecosystems investigated in the Khibiny in 2008-2018. 


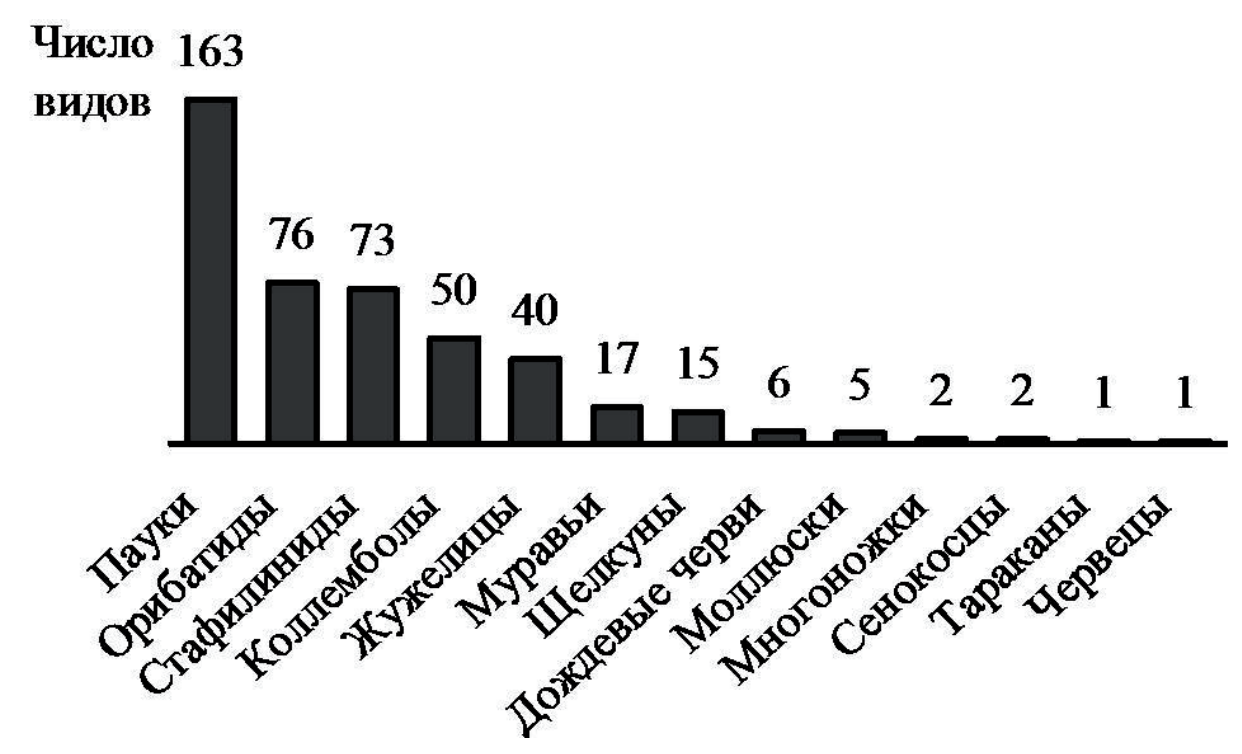

Рис. 2. Видовое разнообразие основных таксонов беспозвоночных, выявленных в почвах Хибин за период 2008-2018 гг.

Fig. 2. Species diversity of invertebrate animals identified in the Khibiny soils in 2008-2018.

2014; Зенкова, 2014а,б; Зенкова, Мелехина, 2014; Зенкова, Юсупов, 2016; Нехаева, 2018; Zenkova, Rapoport, 2014; Nekhaeva, 2015; Zenkova, 2016; Zenkova, Filippov, 2019). К настоящему времени они выполнены на склонах десяти гор (рис. 1) в еловых и сосновых лесах горно-таежного пояса в диапазоне высот 250-390 метров над ур. м., в поясах березовых криволесий (280-490 м), горной тундры (385-730 м) и каменистой пустыни с фрагментарной растительностью на высокогорных плато (1020-1093 м). С 2015 г. ведется зоологический мониторинг восстановительных сукцессий на антропогенно нарушенных территориях (вырубки и гари) в межгорной долине реки Кунийок.

Выявлено более 450 в. беспозвоночных - обитателей органогенного горизонта горных почв и яруса напочвенной растительности. Наиболее разнообразны паукообразные (пауки, сенокосцы, панцирные клещи-орибатиды, всего 241 в.) и насекомые. Определено 50 в. первичнобескрылых насекомых - коллембол, 17 в. муравьев, 126 в. жесткокрылых. Число видов дождевых червей, моллюсков и многоножек в горах ограничено (рис. 2). Десятки видов беспозвоночных оказались либо новыми для Хибин, либо не известными для Мурманской области за пределами массива. В числе последних - 20 в. и одно новое семейство (Titanoecidae) пауков, 16 в. стафилинид, 11 в. жужелиц, 7 в. коллембол, 3 в. панцирных клещей, восточноевропейско-азиатский дождевой червь Eisenia nordenskioldi, широко расселившийся в Сибири. Пять видов пауков (Agroeca lusatica, Agyneta affinis, A. rurestris, Dicymbium nigrum, Gnaphosa bicolor) обнаружены в Хибинах на северном пределе распространения. Единичные находки редкой краснокнижной жужелицы блестящей Carabus nitens известны из зональной тундры на побережье Баренцева моря. В пределах лесной зоны Мурманской области это красивый нелетающий жук сохранился в тундровых экосистемах Хибин (Зенкова, 2019).

При всем многообразии видов типичными для Хибин, встреченными в большинстве горнолесных и горно-тундровых биоценозов, является их незначительная часть. Из 6 в. дождевых червей широко распространены мелко- и среднеразмерные подстилочные Dendrobaena octaedra, Dendrodrilus rubidus и почвенно-подстилочный Lumbricus rubellus. Крупные виды - почвенный Aporrectodea caliginosa и термофильный компостный Eisenia fetida выявлены в интразональных березняках разнотравных на склонах Ю-ЮВ экспозиции. Только в таких биоценозах с мощной подстилкой единичны многоножки-землянки Geophilus proximus, тогда как полизональная костянка Lithobius (Monotarsobius) curtipes распространена во всех поясах Хибин, включая гольцовые пустыни. Из 5 в. моллюсков обычен слизень Arion subfuscus, в лесных подстилках - раковинные моллюски Discus ruderatus и Perpolita petronella. Улитки Euconulus fulvus и Zoogenetes harpa предпочитают опад лиственных пород в поясе березовых криволесий; последний вид встречается и в под- 
бурах горной тундры. Из 126 в. жесткокрылых - представителей семейств Staphilinidae, Carabidae, Elateridae в Хибинах обычны лишь два десятка видов: 5 в. щелкунов и по 7 в. стафилинид (с преобладанием стратобионтов подстилочных) и жужелиц. Из 163 в. пауков методами почвенных проб и ловушек с формалином часто учтены не более 2-х десятков видов. Среди 76 в. орибатид лишь 9 в. обитают в большинстве горно-таежных и горно-тундровых экосистем, от 8 до $35 \%$ видов встречены лишь в одном местообитании. Из 50 в. коллембол наиболее распространены 5 в. семейства Isotomidae, включая аркто-альпийский вид Tetracanthella wahlgreni. Значительная доля видов почвенной фауны отловлена в единственном экземпляре: 26 в. пауков, 11 в. стафилинид, 9 в. жужелиц, 6 в. щелкунов и муравей европейско-западносибирского вида $F$. rufibarbis, локально распространенного в южной Фенноскандии до широты $62^{\circ}$.

Почвенная фауна горно-лесных поясов Хибин в целом сохраняет ядро доминантов, характерных для подзолов зональной северной тайги Мурманской области (двукрылые, жесткокрылые, пауки, многоножки, энхитреиды, дождевые черви), но обеднена насекомыми разных трофических уровней. Наиболее близки к зональным подзолам показатели численности и таксономический состав беспозвоночных на горных склонах С и СВ экспозиции. На склонах Ю и ЮВ экспозиции, в условиях более благоприятного гидротермического режима почв, сформировались интразональные лесные биоценозы с наибольшим таксономическим и экологическим разнообразием фауны и высокой функциональной активностью сапрофагов (дождевых червей, энхитреид, моллюсков, личинок жуков-щелкунов), что нетипично для северотаежных подзолов. Расширенный спектр видов и жизненных форм дождевых червей связан с повышенным содержанием кальция и органического вещества в горных почвах, которые относятся к многогумусному типу (Переверзев, 2010). По спектру жизненных форм дождевые черви Хибин образуют сукцессионный ряд: подстилочные $\rightarrow$ подстилочно-почвенные $\rightarrow$ почвенные, который соответствует стадийности процесса деструкции растительного опада и свидетельствует о более глубокой степени биотрансформации органического вещества в горно-лесных почвах по сравнению с подзолами северо-таежной подзоны Мурманской области.

Горные тундры, напортив, отличаются от зональной тундры Мурманской области повышенными показателями численности и разнообразия почвенной фауны, сопоставимыми с зональной северной тайгой. Это объясняется более мягкими климатическими условиями в высокогорных поясах Хибин в связи с положением массива в подзоне северной тайги, а самих горных тундр - на относительно небольших высотах. О мягкости горного климата свидетельствует «таежный облик» фауны и массовое проникновение лесных видов в пояса горной лесотундры и тундры. Именно к этим поясам приурочено наибольшее разнообразие пауков, жужелиц, щелкунов и активно летающих насекомых.

Вклад в разнообразие фауны горных тундр Хибин вносят и немногочисленные, но не характерные для равнинной территории Мурманской области арктоальпийские и аркто-бореомонтанные виды. Арктоальпийскими являются паук Acantholycosa norvegica и коллембола Tetracanthella wahlgren. Аркто-бореальное распространение имеют панцирные клещи Ceratoppia sphaerica, Heminothrus punctatus, Diapterobates notatus и 5 в. пауков, в т.ч. чрезвычайно редкий для Фенноскандии Arctobius agelenoidesa. Список дополняют виды с узким фенноскандинавским ареалом (паук Oreoneta sinuosa), тундровые виды коллембол (Desoria multisetis) и жужелиц (Curtonotus alpinus, Miscodera arctica), обитатели альпийских экосистем и высокогорных ледников (панцирный клещ Mycobates tridactylus), муравьи борео-альпийского вида Formica suecica и единственного в подсемействе Formicinae приполярного вида $F$. gagatoides. Особенностью фауны беспозвоночных Хибин, как заполярного массива, можно считать отсутствие арктических видов, даже в экосистемах высокогорной тундры и гольцовой пустыни.

Учитывая сложный пересеченный рельеф, специфический горный микроклимат, выраженную высотную поясность, гетерогенный почвенный покров и щелочной состав почвообразующих пород (нефелиновых сиенитов), следует ожидать расширения фаунистических списков при дальнейших исследованиях Хибинского и Ловозерского горных массивов. Это могут быть как широкоареальные, так и стенотопные виды: термофильные, фотофильные, кальцефильные, а также виды, тяготеющие к Арктике. 


\section{Благодарность}

Автор глубоко признателен всем участникам хибинских экспедиций и специалистам, выполнившим таксономические определения беспозвоночных.

Исследования выполнены в рамках тем НИР №№ 01201350346 и 0226-2019-0065 и при поддержке Программы фундаментальных исследований Президиума РАН П-30 «Живая природа» (2012-2014) и грантов РФФИ (12-04-01538-a, 16-04-01878-а и 17-44-510841-p_a).

\section{Литература}

1. Ануфриев Г.А. О фауне цикадовых (Homoptera, Cicadinea) проектируемого национального парка «Хибины» / Чтения памяти проф. В.В. Станчинского. Вып. 3. Смоленск. 2000. С. 24-26.

2. Гуцевич А.В. О комарах из Хибинских гор // Паразитологический сборник Зоол. ин-та Акад. наук СССР. Л.: изд. АН СССР. 1934. Т. 6. С. 5-17.

3. Зенкова И.В. Особенности организации почвенной фауны в горных экосистемах Кольского Заполярья / Проблемы почвенной зоологии. М.: КМК. 2014 а. С. 98-100.

4. Зенкова И.В. Типичные и редкие виды беспозвоночных в почвах Хибин / Горные экосистемы и их компоненты. Нальчик: ИЭГТ КБНЦ РАН. 2014 б. С. 101-102.

5. Зенкова И.В. Материалы к распространению редкой жужелицы Carabus nitens L. (Coleoptera, Carabidae) в Мурманской области // Труды Карельского НЦ РАН. 2019. Серия Биогеография. № 8. С. 132-150. DOI: $10.17076 / \mathrm{bg} 979$.

6. Зенкова И.В., Пожарская В.В., Похилько А.А. Материалы к почвенной фауне Хибинского горного массива на примере горы Вудъяврчорр // Вестник МГТУ. 2009. Т. 12. № 3. С. 516-524.

7. Зенкова И.В., Зайцев А.С., Залиш Л.В., Лисковая А.А. Почвообитающие панцирные клещи (Acariformes: Oribatida) таежной и тундровой зон Мурманской области // Труды Карельского НЦ РАН. 2011а. № 1. C. 54-67.

8. Зенкова И.В., Пожарская В.В., Похилько А.А. Высотное распределение почвенной фауны Хибин // Почвоведение. 2011 б. № 9. С. 1083-1093.

9. Зенкова И.В., Пожарская В.В., Филиппов Б.Ю., Колесникова А.А., Середюк С.Д. Высотная поясность и комплексы жесткокрылых в почвах Хибинского горного массива // Труды Карельского НЦ РАН. 2011 в. № 2. C. $107-118$.

10. Зенкова И.В., Мелехина Е.Н. Панцирные клещи (Acari: Oribatida) Хибинского горного массива / Экологические проблемы северных регионов и пути их решения. Апатиты: КНЦ РАН. 2014. С. Ч. 1. С. 135-140.

11. Зенкова И.В., Таскаева А.А. Материалы к фауне микроартропод Хибинского горного массива / Горные экосистемы и их компоненты. Нальчик: «Полиграфсервис и Т». 2012. С. 146-147.

12. Зенкова И.В., Таскаева А.А. Первичные материалы о коллемболах (Insecta: Collembola) пояса полярной пустыни Хибин / Проблемы изучения и охраны животного мира на Севере. Сыктывкар: ИБ Коми НЦ. 2013. С. $85-86$.

13. Зенкова И.В., Юсупов 3.М. Материалы к мирмекофауне Хибинского горного массива / Научные исследования в заповедниках и национальных парках России. Петрозаводск: КНЦ РАН. 2016. С. 84-85.

14. Камаев И.О. Население пауков (Aranei) в высотном градиенте Хибин / Ломоносов-2010. М.: МАКСПресс. 2010. С. 126-127.

15. Леонов В.Д., Рахлеева А.А. Состав и распределение сообществ микроартропод в ландшафтноэкологическом профиле высотной поясности горы Вудъяврчорр (Мурманская область, Хибинские горы) // Известия Пензенского гос. пед. ун-та им. Белинского. Естественные науки. 2011. № 25. С. 376-382.

16. Леонов В.Д., Рахлеева А.А. К вопросу о сходстве и различиях горных и равнинных тундр Кольского полуострова на основе данных по панцирным клещам (Acari: Oribatida) // Евразиатский энтомол. журнал. 2015. Т. 14. № 5. С. 489-499.

17. Нехаева А.А. Фауна и население пауков (Arachnida, Aranei) Кольского полуострова. Автореф. дисс. ... канд. биол. наук. Москва. 2018. 23 с.

18. Переверзев В.Н. Генетические особенности почв природных поясов Хибинских гор (Кольский полуостров) // Почвоведение. 2010. № 5. С. 548-557.

19. Перель Т.С. Распространение и закономерности распределения дождевых червей фауны СССР. М. Изд-во: Наука. 1979. 272 с.

20. Пожарская В.В. Почвообитающие беспозвоночные в экосистемах Хибинского горного массива. Автореф. дисс. ... канд. биол. наук. Петрозаводск. 2012. 21 с.

21. Потапов Г.С., Колосова Ю.С. Фауна и зоогеографическая характеристика шмелей (Hymenoptera, Apidae: Bombus) Хибин // Евраз. энтомол. журн. 2011. Т. 10. № 4. С. 483-485. 
22. Россолимо Т.Е. Высотное распределение и термопреферендум жужелиц в Хибинах // Зоологический журнал. 1989. Т. 68. № 4. С. 58-65.

23. Россолимо Т.Е. Сравнительный анализ параметров холодостойкости некоторых жесткокрылых (Coleoptera) гипоарктических районов // Зоологический журнал. 1994. Т. 73. № 7-8. С. 101-113.

24. Рыбалов Л.Б. Сравнительная характеристика населения дождевых червей в Карелии и полярноальпийском ботаническом саду на Кольском полуострове // Современные экологические проблемы Севера. Апатиты: КНЦ РАН. 2006. Ч. 2. С. 176-177.

25. Старк В.Н. Короеды Хибинского массива // Защита растений от вредителей. 1931. Т. 7. № 1-3. С. 19-28.

26. Танасевич А.В., Камаев И.О. Пауки Кольского полуострова (Arachnida: Aranei) // Кавказский энтомол. бюллетень. 2011. Т. 7. № 1. С. 7-32.

27. Таскаева А.А. Фауна и население коллембол (Collembola) горных экосистем Хибин и Урала / Экологические проблемы северных регионов и пути их решения. Апатиты: КНЦ РАН. 2014. Ч. 3. C. 82-84.

28. Татаринов А.Г., Кулакова О.И. Локальные фауны булавоусых чешуекрылых (Lepidoptera: Papilionoidea, Hesperioidea) Европейского Севера России: Хибины // Вестник Поморского ун-та. Сер. Естественные и точные науки. 2009. № 1. С. 68-76.

29. Фридолин В.Ю. Изучение насекомых Хибинских гор в связи с вопросами колонизации края // Хибинские апатиты. 1931. Т. 2. С. 446-451.

30. Фридолин В.Ю. Зоогеографические и биоценотические исследования в Хибинских горах // Экспедиции Всесоюзной Академии наук. 1931 год. Л. Изд-во: АН СССР. 1932. С. 334-341.

31. Фридолин В.Ю. Значение элементов рельефа как оазисов-убежищ реликтовой фауны в бассейне Финского залива, Хибинских горах и центральной Карелии // Труды I Всесоюзн. геогр. съезда. Л. 1934. Вып. 3. С. 294-307.

32. Фридолин В.Ю. Животно-растительное сообщество горной страны Хибин. М.-Л. Изд-во: АН СССР. 1936. 293 с.

33. Эколого-экономическое обоснование национального парка «Хибины» / Отчет по Контракту № 003-98 от 25.05.1998. «Работы по проектированию особо охраняемых природных территорий в Мурманской области». Апатиты: ИППЭС КНЦ РАН. 1999. 297 с.

34. Karppinen E., Krivolutsky D.A. List of oribatid mites (Acarina, Oribatei) of northern palaearctic region. 1. Europe // Acta Entomol. Fennica. 1982. V. 41. P. 1-18.

35. Nekhaeva A.A. An annotated checklist of spiders (Arachnida: Aranei) of the Khibiny Mountains, Kola Peninsula, Russia // Arthropoda Selecta. 2015. V. 24. № 4. P. 451-472.

36. Poppius B.R. Kola-halfons och Enare Lappmark Coleoptera / Festschrift Herrn Professor Dr. J.A. Palmen. Helsingfors: Aktiebolaget Handelstryckeriet. 1905. Bd. 2. Hf. 2. S. 1-200.

37. Zenkova I.V. Myriapods (Myriapoda) occurring on plains and in mountain ecosystems on the Kola Peninsula (Russia) // Acta Societatis Zoologicae Bohemicae. 2016. V. 80. Special Issue: Proceedings of the 16th International Congress of Myriapodology, 16 ICM. № 1. P. 87-99.

38. Zenkova I.V., Rapoport I.B. Species richness and high altitude distribution of earthworms in the Khibiny Mountain Massive (Murmansk Region) / Advances in Earthworm Taxonomy VI (Annelida: Oligochaeta). Heidelberg: Kasparek Verlag. 2014. P. 141-151.

39. Zenkova I., Filippov B. The ground beetles fauna (Coleoptera, Carabidae) of natural and anthropogenic habitats in Khibiny polar mountain massif / 8th International Symposium of Ecologists - ISEM8. Podgorica, Institute for Biodiversity and Ecology. 2019. P. 121-129. 